\title{
Nurses' experiences of the causes of their lack of interest in working in psychiatric wards: a qualitative study
}

Narges Rahmani

Islamic Azad University

Eesa Mohammadi ( $\nabla$ Mohamade@modares.ac.ir)

Tarbiat Modares University

Masoud Fallahi-Khoshknab

University of Social Welfare and Rehabilitation Sciences

\section{Research Article}

Keywords: Psychiatric nurse, Qualitative study, Interest

Posted Date: April 9th, 2021

DOI: https://doi.org/10.21203/rs.3.rs-389352/v1

License: (c) (i) This work is licensed under a Creative Commons Attribution 4.0 International License.

Read Full License

Version of Record: A version of this preprint was published at BMC Nursing on December 1st, 2021. See the published version at https://doi.org/10.1186/s12912-021-00766-1. 


\section{Abstract}

Background:The shortage of psychiatric nurses is a major healthcare challenge. Lack of interest (LOI) is a significant factor contributing to the shortage of psychiatric nurses. Nonetheless, there are limited studies in this area. The present study was conducted to explore nurses' experiences of the causes of their LOI in working in psychiatric wards.

Methods:This qualitative study was conducted in 2016-2019 using the content analysis approach. Participants were 27 nurses purposively recruited with maximum variation from the psychiatric wards of three referral hospitals in Iran. Data were collected via unstructured interviews and were concurrently analyzed using the conventional content analysis approach recommended by Graneheim and Lundman.

Results: The causes of participants' LOI in working in psychiatric wards were grouped into three main categories, namely inadequate professional skills for psychiatric care practice, negative public attitude towards psychiatric nurses, and concerns over patients.

Conclusion: This study suggests that the causes of nurses' LOI in working in psychiatric wards are not only personal, but also social and organizational. Findings help managers and authorities develop strategies to increase psychiatric nurses' interest in working in psychiatric wards through improving their work conditions and professional knowledge and skills.

\section{Background}

With high prevalence and heavy disease burden, psychiatric disorders are among the major healthcare challenges (1). According to the World Health Organization report, 450 million people in the world suffer from psychiatric disorders, mainly major depression (2). This organization also reports that $25 \%$ of people suffer from one or more psychiatric disorders in each stage of life(3). A study in Iran also showed that in 2003 , mental and behavioral disorders were responsible for $16 \%$ of total disease burden and were the second highest ranked disorders respecting disease burden (1).

Patients with psychiatric disorders are at high risk for death due to suffering from different comorbid physical conditions, comorbid cognitive impairments, refusal of treatment, and healthcare providers' biases (4). Moreover, these patients need to use multiple medications, are at risk for medication side effects, have unhealthy lifestyle, are overweight or obese, use tobacco, and hence, need quality healthcare services (5). Quality healthcare delivery in turn depends on the availability of competent and committed healthcare providers, including nurses.

Nurses are the largest group of healthcare providers in psychiatric hospitals. The main goals of nursing care in these hospitals are to provide quality care to patients in order to facilitate their recovery and help them return to normal life. Consequently, quality nursing care services can help patients in psychiatric hospitals more rapidly return to normal life and prevent their re-hospitalization (6). Nonetheless, there are inadequate nurses for psychiatric care delivery. The World Health Organization reported that in 2014, 
there were less than one psychiatrist and 7.7 nurses per 100000 patients in psychiatric settings, implying severe shortage of psychiatric care providers (2).

Nurses' lack of interest (LOI) in working in psychiatric settings is a major factor contributing to the shortage of nursing staff in these settings. A study reported that most nurses choose to work in psychiatric settings only when there is no other employment opportunity (7). Factors affecting their interest in working in psychiatric settings are their negative attitudes towards work in these settings (8), stress, and emotional burnout (9). A study reported that more than half of the nurses in psychiatric settings suffer from severe stress and emotional burnout (9). Another study also reported that psychiatric nurses experience high levels of occupational stress which negatively affect their care quality and cause them job burnout, fear, despair, and dissatisfaction, particularly in the first fifteen months of their work in psychiatric settings (10). Moreover, a study showed that nursing students are not willing to work in psychiatric settings due to different stressors associated with work in these settings, emotional burnout, and negative public attitudes towards psychiatric settings (11). Other causes for nurses' LOI in working in psychiatric settings include lack of technical nursing practice in these settings (12) and stressful work conditions (13).

Despite the great importance of interest in work for the shortage of psychiatric nurses and the quality of psychiatric nursing care $(5,14,15)$, limited studies have so far addressed the causes of LOI among psychiatric nurses. The handful of studies in this area also dealt mainly with medical students' LOI (16) or the sources of stress among psychiatric nurses(11). Moreover, there are limited data, if any, in this area in Iran. Therefore, the present study was conducted to address this gap. The aim of the study was to explore nurses' experiences of the causes of their LOI in working in psychiatric wards.

\section{Methods}

This qualitative study was conducted in 2016-2019 using the content analysis approach. Qualitative research provides the opportunity to explore experiences in natural environment and is useful for studying poorly known phenomena.

Study setting was the psychiatric wards of two referral hospitals in Mazandarn province in the north of Iran and a referral psychiatric hospital in Tehran, Iran (17). Participants were 27 hospital nurses purposively recruited to the study. Inclusion criteria were ability to communicate verbally and working in psychiatric ward. Sampling was done with maximum variation with respect to eligible participants' gender, educational level, work experience, and affiliated ward in order to collect more in-depth data.

Data were collected via personal unstructured interviews which were started using a broad open-ended question, i.e. "May you please talk about you interest in working in this ward?" Then, clarifying questions were used based on participants' responses. Examples of these questions were "Can you please explain more?" "What do you mean by this?" Data collection was continued up to the point at which no new data were obtained from the last three interviews. The length of the interviews was 32 minutes, on average. All interviews were held in a quiet room in participants' workplace and were recorded with their consent. 
The conventional content analysis approach recommended by Graneheim and Lundman was used for data analysis. The first author primarily listened to each interview for several times and transcribed it in order to get familiar with the data. Then, meaning units were identified and coded and the codes were grouped into more abstract subcategories according to their similarities. Subcategories were also compared with each other and grouped into main categories (18). Table 1 shows a sample of data analysis.

Table 1

An example of data analysis

\begin{tabular}{|llll|}
\hline Meaning units & Primary codes & Subcategories & Categories \\
\hline $\begin{array}{l}\text { I feared patients with schizophrenia, } \\
\text { specifically those who were tall and } \\
\text { giant. They look at you in a different } \\
\text { way (P. 23). }\end{array}$ & $\begin{array}{l}\text { Fear over patients with } \\
\text { schizophrenia } \\
\text { Occupational stress due to } \\
\text { feeling insecure }\end{array}$ & $\begin{array}{l}\text { Fear over } \\
\text { patient } \\
\text { assault }\end{array}$ & $\begin{array}{l}\text { Concerns } \\
\text { over } \\
\text { patients }\end{array}$ \\
$\begin{array}{l}\text { Occupational stress and fear are very } \\
\text { great. Of course, outsiders may not } \\
\text { feel so (P. 18). }\end{array}$ & & \\
$\begin{array}{l}\text { In the first days, I had fear over patient } \\
\text { assault due to my limited knowledge } \\
\text { about them and their conditions (P. }\end{array}$ & $\begin{array}{l}\text { Fear over being injured by } \\
\text { patients due to having little } \\
\text { knowledge about them, } \\
\text { their conditions, and how to } \\
\text { establish effective } \\
\text { I had not adequately experienced }\end{array}$ & $\begin{array}{l}\text { Fear due to } \\
\text { unfamiliarity } \\
\text { with patients } \\
\text { and their } \\
\text { conditions }\end{array}$ & \\
$\begin{array}{l}\text { studentshic wards during my } \\
\text { in the first days of my work in this } \\
\text { ward even when I wanted to establish } \\
\text { effective communication with patients }\end{array}$ & & & \\
(P. 20). & & & \\
\end{tabular}

Trustworthiness was established via the four criteria of credibility, dependability, confirmability, and transferability (17). To ensure credibility, the first author had direct communication with participants over a course of twelve months. Dependability was ensured through providing excerpts from the data together with their corresponding codes to participants in order to compare them with their own experiences. To ensure confirmability, two of the authors assessed and commented on the generated codes and categories. Sampling with maximum variation with respect to participants' gender, educational level, and affiliated ward also helped ensure transferability.

The Ethics Committee of Tarbiat Modares University, Tehran, Iran, approved this study (code: IR.TMU.REC.1394.169). Participants received clear information about the aim of the study and interviews were held according to their preference. They were ensured about their freedom to voluntarily withdraw from the study, the confidentiality of their data, and their access to the study findings at will. Necessary permissions for the study were also obtained from the authorities of the study setting. 


\section{Results}

Study participants were 27 nurses from three referral hospitals in Iran. Their age mean was 8.1 years. Most participants were female (fourteen participants), had bachelor's degree (21 participants), and worked in acute care wards (twenty participants).

Participants' experiences of the causes of their LOI in working in psychiatric wards were grouped into eight subcategories and three main categories, namely inadequate professional skills for psychiatric care practice, negative public attitudes towards psychiatric nurses, and concerns over patients (Table 2).

Table 2

The subcategories and categories of the study

\section{Subcategories}

Forced choice of working in psychiatric wards

Inappropriate work conditions

Lack of the required professional knowledge for working in psychiatric wards

Colleagues' negative attitudes towards psychiatric nurses

Families' negative attitudes towards psychiatric nurses

Negative experiences of psychiatric nursing from their studentship period

Fear over patient assault Concerns over patients

Fear due to unfamiliarity with patients and their conditions

1. Inadequate professional skills for psychiatric care practice

Inadequate professional skills for psychiatric care practice was one of the main causes of LOI among participants. Participants noted that they were not ready enough for psychiatric care practice when starting their work in psychiatric wards and had chosen this work because they had no more option. They considered work in psychiatric wards to be harder than work in other hospital wards due to factors such as insignificant patient recovery, limited readiness for work, and finding no pleasure at work. The subcategories of this category were forced choice of working in psychiatric wards, inappropriate work conditions, and lack of the necessary professional knowledge for working in psychiatric wards.

\subsection{Forced choice of working in psychiatric wards}

Most participants reported that they were compelled to work in psychiatric wards due to their own physical problems, heavy workload in other wards, or nursing staff shortage in psychiatric wards. Some 
of them also noted that they chose to work in psychiatric wards due to its advantages such as lower working hours, earlier retirement, no night shift, and more leaves.

I had undergone a surgery and my doctor had emphasized that I shouldn't work in infectious diseases wards. Therefore, I chose psychiatric care practice, stayed in it, and couldn't change it. I chose it without any interest (P. 19; a male nurse with a ten-year work experience).

\subsection{Inappropriate work conditions}

Participants reported that they had limited interest in working in psychiatric wards due to repetitious nature of work in these wards, limited patient recovery, patients' frequent re-hospitalizations, their own limited readiness for psychiatric care practice, and subsequent considerable occupational strain. They also noted that their unfamiliarity with working in psychiatric wards, management of patients with psychiatric disorders, and medication administration contributed to their LOI for working in these wards.

I cried a lot the first day I came here. I didn't like to be here. Patients with psychiatric disorders never achieve complete recovery. We don't have a pleasant feeling of nursing practice here; I mean a feeling that results from patient recovery (P. 16; a female nurse with a seven-year work experience).

\subsection{Lack of the necessary professional knowledge for working in psychiatric wards}

Participants reported that nurses in psychiatric wards have lower levels of professional knowledge compared with nurses in other hospital wards. They also referred to wide theory-practice gap in psychiatric wards and described these wards as wards with repetitious patients and limited range of diagnoses. Accordingly, they noted that they had limited interest in work, had fallen behind their colleagues in other wards respecting professional competence, and had been fossilized.

I didn't have any interest in working in this ward because working in this ward lowers your professional level and knowledge. Repetitive tasks in these wards have resulted in rote learning and routine practice. When you stop doing these routine tasks for a while, you easily forget them. I know that I have fallen behind my peers in other wards (P. 14; a female nurse with a seventeen-year work experience).

2. Negative public attitudes towards psychiatric nurses

Negative public attitudes towards psychiatric nurses was another main cause of LOI in working in psychiatric wards. Participants noted that people, including their family members and relatives, have misconceptions and negative images about working in psychiatric hospitals and hence, psychiatric nurses feel compelled to hide the name of their workplace from others despite several years of work experience in psychiatric wards. They reported family members' and colleagues' negative attitudes towards psychiatric nursing and their own past experiences during their university education as causes of their LOI in working in psychiatric wards. The subcategories of this category were colleagues' negative 
attitudes towards psychiatric nurses, families' negative attitudes towards psychiatric nurses, and negative experiences of psychiatric nursing from their studentship period.

\subsection{Colleagues' negative attitudes towards psychiatric nurses}

Participants reported that their colleagues in other hospital wards had negative attitudes towards psychiatric nurses, asked them to change their workplace, and had asked them not to choose working in psychiatric settings at the time of employment. These factors had negatively affected their interest in working in psychiatric wards.

Previously, I was in another hospital. When I successfully passed the employment exam, a nurse asked me whether I could change my workplace. It greatly disappointed me (P. 24; a female nurse with a fourteen-year work experience).

\subsection{Families' negative attitudes towards psychiatric nurses}

Participants noted that their family members and significant others had negative attitudes towards psychiatric nurses and did not have accurate understanding about psychiatric hospitals and patients. Therefore, our participants attempted to hide the name of their workplace from others. Family members' negative attitudes had negatively affected their mood, caused them preoccupation with their work, and reduced their interest for work. They reported that their significant others considered psychiatric hospitals as a place for keeping patients rather than as medical centers and believed that patients in these centers were in chain.

I had no interest for working in psychiatric ward. I feel whatever I explain to my significant others, they don't understand and just say that I work in madhouse (P. 17; a female nurse with a two-year work experience).

\subsection{Negative experiences of psychiatric nursing from their studentship period}

Participants noted that they had negative experiences and image of psychiatric nursing from their studentship period and hence, were not interested in working in psychiatric wards. Some of them reported that they had experienced patient assault during their studentship in psychiatric wards.

I didn't like psychiatric wards from my studentship period because studentship in these wards had greatly affected me. Those days, I thought to myself that I would never choose working in psychiatric wards (P. 21; a female nurse with a six-year work experience).

\section{Concerns over patients}

Fear over patient assault and unfamiliarity with patients were also among the causes of participants' LOI in working in psychiatric wards. They noted that due to the negative attitudes of their friends, colleagues, 
and significant others towards patients with psychiatric disorders, they felt fear when they heard the expression "patients with psychiatric disorders" at the time of starting their work in psychiatric wards, attempted not to get close to them, and had anxiety over working in psychiatric wards. The two subcategories of this category were fear over patient assault and fear due to unfamiliarity with patients and their conditions.

\subsection{Fear over patient assault}

Participants had fear over patient assault because they believed that patients with psychiatric disorders might become irritable and aggressive. They were mostly concerned with assault by patients with schizophrenia due to their delusions and hallucinations, patients with paranoia, and physically strong patients. Such fear was a major cause for their LOI in working in psychiatric wards.

I didn't like to work here due to my fear over patient irritability. Patients with psychiatric disorders may suddenly become irritable and aggressive and attack you. I had fear over injury to myself (P. 24; a female nurse with a fourteen-year work experience who worked in men's psychiatric ward).

\subsection{Fear due to unfamiliarity with patients and their conditions}

Participants expressed that they were not interested in working in psychiatric wards due to their unfamiliarity with patients with psychiatric disorders and their unique characteristics. They were not familiar with these patients and their symptoms and hence, felt fear when witnessed conditions such as panic attacks. They noted that they did not know how to manage unfamiliar conditions and hence, experienced high levels of stress.

In the first days, I had no knowledge about these patients and their problems and hence, I feared them and didn't want to work in this ward (P. 21; a female nurse with a six-year work experience).

\section{Discussion}

This study revealed that the causes of nurses' LOI in working in psychiatric wards were inadequate professional skills for psychiatric care practice, negative public attitudes towards psychiatric nurses, and concerns over patients.

One of the main causes of LOI in working in psychiatric wards was inadequate professional skills for psychiatric care practice. Participants noted that their forced choice of working in psychiatric wards, inappropriate work conditions, patients' insignificant recovery, and lack of the necessary professional knowledge for working in psychiatric wards contributed to their LOI in working in psychiatric wards. In line with these findings, a former study reported that nurses who were employed for working in psychiatric wards did not take appropriate ward orientation courses and had to immediately start working due to staff shortage (19). Another study showed that most psychiatric nurses would quit nursing during the first twelve months after graduation due to factors such as heavy workload, poorly defined career 
structure, and limited number of experienced physicians (20). Moreover, a study reported that psychiatric nurses with closer professional relationships with patients had more positive attitudes towards working in psychiatric wards (13). Education is a major factor affecting students' and nurses' interest in work. Therefore, providing them with quality education about skills and competencies for psychiatric nursing practice can increase their interest. Using experienced nurses for supervising and mentoring novice nurses can also increase nurses' interest in working in psychiatric wards. A former study highlighted that improving nursing students' theoretical and practical knowledge was effective in developing positive attitudes towards psychiatric nursing (21).

The second main category of the causes of nurses' LOI in working in psychiatric wards was negative public attitudes towards psychiatric nurses. Participants noted that their colleagues' and families' negative attitudes towards psychiatric nurses and their own negative past experiences of psychiatric nursing contributed to their LOI. Two former studies also reported that negative attitudes towards psychiatric nurses negatively affect nurses' interest in working in psychiatric wards and their morale (20, 22). Another study reported that fear over social stigmatization prevented psychiatric nurses from informing their friends and families about their workplace (19). Most people have false ancient beliefs about mental disorders. For example, they consider afflicted patients as dangerous, unpredictable, and inefficient. These beliefs also negatively affect people who care for these patients, including healthcare providers. Therefore, these beliefs negatively affect psychiatric care quality and the prospect of psychiatric and mental health nursing. Some nurses may also hold the same beliefs which can make them angry in their communications with these patients, cause them to think that these patients do not deserve help and support, and reduce their interest in working in psychiatric wards (23). Moreover, significant others' negative attitudes and beliefs about patients with psychiatric disorders and psychiatric nurses negatively affect nurses' morale and cause them intense preoccupation with their work. These problems are mostly prevalent among psychiatric nurses, while nurses in other hospital wards may have positive feelings about their work, particularly at the time of employment (24-27).

Concerns over patients was the third main category of the study. Participants noted that their fear over patient assault and their unfamiliarity with psychiatric wards and patients significantly affected their interest in working in psychiatric wards. Consequently, they preferred to work in wards where they do not experience fear and anxiety. A former study in Iran also reported that novice psychiatric nurses were not interested in working in psychiatric wards due to their fear over unexpected events and affliction by psychiatric disorders (19). Another study showed that psychiatric nurses had fear over communicating with patients and attending psychiatric wards (13). Patients' irritability and aggressiveness and subsequent feeling of insecurity among nurses cause them fear and stress (25-28). Psychiatric nurses usually have fear over patient assault, while nurses in other wards have fear over committing errors and causing injuries to patients. Nursing students also have fear over attending psychiatric wards because they may believe that patients with psychiatric disorders are dangerous. Therefore, interventions are needed to develop positive attitudes about psychiatric wards among students. An example of such interventions is the provision of the opportunity for having clinical experiences (8). 


\section{Conclusion}

This study shows that the major causes of nurses' LOI in working in psychiatric wards are their inadequate professional skills for psychiatric care practice, negative public attitudes towards psychiatric nurses, and concerns over patients with psychiatric disorders. Nurses in psychiatric wards lack knowledge and familiarity regarding psychiatric care practice and psychiatric wards and choose working in these wards when they have no more option. Their interest in working in psychiatric wards is also affected by their families' and colleagues' attitudes towards psychiatric nursing, their own past experiences in this area, and their fear and anxiety over patient assault.

Novice nurses have limited interest in working in psychiatric wards. The findings of the present study showed that the causes of nurses' LOI in working in psychiatric wards include their inadequate professional skills for psychiatric care practice, negative public attitudes towards psychiatric nurses, and concerns over patients with psychiatric disorders. Healthcare managers and authorities can use the findings of the present study to improve psychiatric nurses' work conditions and thereby increase their interest in working in psychiatric wards. Media-based interventions are also needed to modify public attitudes towards patients with psychiatric disorders and their healthcare providers. Such interventions may increase nurses' interest in working in psychiatric wards and improve the quality of their care services.

\section{Abbreviations}

LOI: Lack of interest

\section{Declarations}

\section{Ethics approval and consent to participate}

The Ethics Committee of Tarbiat Modares University, Tehran, Iran, approved this study (code: IR.TMU.REC.1394.169). Since all participants were over 16 years old, informed consent letter was obtained from all the participants before the start of the study. all methods were carried out in accordance with relevant guidelines and regulations in the Ethical Declarations.

\section{Consent for publication}

Not Applicable.

\section{Availability of data and materials}

The datasets generated and/or analysed during the current study are not publicly available due [individual privacy could be compromised] but are available from the corresponding author on reasonable request. 


\section{Competing interests}

No conflict of interest has been declared by the authors

\section{Funding}

None.

\section{Authors' contributions}

N.R. undertook the data collection, data analysis, and wrote the manuscript; E.M and M.F.K. supervised the analysis and research process; all the authors read and approved the final manuscript.

\section{Acknowledgement}

This study is part of a PhD thesis at the Faculty of Medical Sciences, Tarbiat Modares University (grant number: 52/7751 Dated 6.12.2015). Hereby, the researchers would like to express their gratitude to the Research Deputy of the university for their support and also all the nurses who cooperated in the project.

\section{References}

1. NOORBALA AA, DAMARI B, RIAZI IS. Evaluation of mental disorders incidence trend in Iran. 2014.

2. Samari E, Seow E, Chua BY, Ong HL, Lau YW, Mahendran R, et al. Attitudes towards psychiatry amongst medical and nursing students in Singapore. BMC medical education. 2019;19(1):91.

3. Sedighi E, Bidaki R, Meidani A, Ahmadinia H, Rezaeian M. Mental Health Status in Medical Students of Rafsanjan University of Medical Sciences in 2016. Journal of Rafsanjan University of Medical Sciences. 2018;17(7):669-80.

4. Dombrovski A, Rosenstock J. Bridging general medicine and psychiatry: providing general medical and preventive care for the severely mentally ill. Current Opinion in Psychiatry. 2004;17(6):523-9.

5. Ebrahimi $\mathrm{H}$, Namdar $\mathrm{H}$, Vahidi M. Quality of nursing care in psychiatric wards of university hospitals in northwest of Iran from the perceptions of nurses. Journal of caring sciences. 2012;1(2):79.

6. Levett-Jones TL. Continuing education for nurses: a necessity or a nicety? The Journal of Continuing Education in Nursing. 2005;36(5):229-33.

7. Atashzadeh-Shoorideh F, Mohtashami J, Pishgooie SAH, Jamshidi T, Sedghi S. Effectiveness of implementation of "mental health nursing students' clinical competency model" on academic performance of nursing students. F1000Research. 2018;7.

8. Jack-Ide I, Amiegheme F, Ongutubor K. Undergraduate nursing students' mental health and psychiatric clinical experience and their career choice in Nursing: perspectives from the Niger delta region of Nigeria. J Ment Disord Treat. 2016;2(2):116-21.

9. Hannigan B, Edwards D, Coyle D, Fothergill A, Burnard P. Burnout in community mental health nurses: findings from the all-Wales stress study. Journal of Psychiatric and Mental health nursing. 
2000;7(2):127-34.

10. Abdalrahim AA. Stress and coping among psychiatric nurses. Middle East Journal of Nursing. 2013;101(665):1-8.

11. Taylor B, Barling J. Identifying sources and effects of carer fatigue and burnout for mental health nurses: a qualitative approach. International Journal of Mental Health Nursing. 2004;13(2):117-25.

12. Happell B, Welch T, Moxham L, Byrne L. Keeping the flame alight: Understanding and enhancing interest in mental health nursing as a career. Archives of psychiatric nursing. 2013;27(4):161-5.

13. Alshowkan A. A qualitative study of attitude towards people with mental illness among nurses in Saudi Arabia. European Psychiatry. 2017;41(S1):S602-S.

14. Akbari Kaji M, Farmahani Farahani B. The effect of nursing process education on nursing care quality of schizophrenic patients. KAUMS Journal (FEYZ). 2011;15(1):32-7.

15. Ramezani T, Fasihi T, Mangali M. Nurses experiences of occupational aggression in the psychiatric wards: Phenomenology approach. 2012.

16. Aslam M, Taj T, Ali A, Badar N, Saeed F, Abbas M, et al. Psychiatry as a career: a survey of factors affecting students' interest in psychiatry as a career. McGill Journal of Medicine: MJM. 2009;12(1):7.

17. Grove SK, Gray JR. Understanding Nursing Research E-Book: Building an Evidence-Based Practice: Elsevier Health Sciences; 2018.

18. Graneheim UH, Lundman B. Qualitative content analysis in nursing research: concepts, procedures and measures to achieve trustworthiness. Nurse education today. 2004;24(2):105-12.

19. Khankeh H, Khorasani-Zavareh D, Hoseini S-A, Khodai-Ardekandi M-R, Ekman S-L, Bohm K, et al. The journey between ideal and real: Experiences of beginners psychiatric nurses. Iranian journal of nursing and midwifery research. 2014;19(4):396.

20. Procter N, Beutel J, Deuter K, Curren D, de Crespigny C, Simon M. The developing role of transition to practice programs for newly graduated mental health nurses. International Journal of Nursing Practice. 2011;17(3):254-61.

21. Happell B, Robins A, Gough K. Developing more positive attitudes towards mental health nursing in undergraduate students: Part 2-the impact of theory and clinical experience. Journal of Psychiatric and Mental Health Nursing. 2008;15(7):527-36.

22. Tingleff EB, Gildberg FA. New graduate nurses in transition: A review of transition programmes and transition experiences within mental health care. International Journal of Mental Health Nursing. 2014;23(6):534-44.

23. Hunter $L$, Weber $T$, Shattell $M$, Harris BA. Nursing students' attitudes about psychiatric mental health nursing. Issues in Mental Health Nursing. 2015;36(1):29-34.

24. Morphet J, Kent B, Plummer V, Considine J. The effect of Transition to Specialty Practice Programs on Australian emergency nurses' professional development, recruitment and retention. Australasian Emergency Nursing Journal. 2015;18(4):204-11.

25. St Clair MB. New graduate nurses' experiences of transition during orientation into critical care. 2013. 
26. La Toya Lewis-Pierre LA, Kovacich J, Hollis L. Workplace readiness of new ICU nurses: A grounded theory study. Glob J Human-Social Sci Res. 2014;14:47-52.

27. Rush KL, Janke R, Duchscher JE, Phillips R, Kaur S. Best practices of formal new graduate transition programs: An integrative review. International journal of nursing studies. 2019;94:139-58.

28. Morphet J, Kent B, Plummer V, Considine J. Transition to Specialty Practice Program characteristics and professional development outcomes. Nurse education today. 2016;44:109-15. 